\title{
Polyarteritis nodosa with perirenal hematoma due to the rupture of a renal artery aneurysm
}

\author{
Taro Miyagawa ${ }^{1,2} \cdot$ Yasunori Iwata $^{1,2,3} \cdot$ Megumi Oshima $^{1,2} \cdot$ Hisayuki Ogura $^{1,2} \cdot$ Koichi Sato $^{1,2} \cdot$ Shiori Nakagawa ${ }^{1,2}$. \\ Yuta Yamamura ${ }^{1,2}$. Shinji Kitajima ${ }^{1,2}$. Tadashi Toyama ${ }^{1,2} \cdot$ Akinori Hara $^{1,2} \cdot$ Satoshi Kokubo ${ }^{1,4} \cdot$ Norihiko Sakai $^{1,2,5}$. \\ Miho Shimizu $^{1,2} \cdot$ Kengo Furuichi $^{6} \cdot$ Takashi Wada $^{1,2}$
}

Received: 12 July 2020 / Accepted: 23 October 2020 / Published online: 11 November 2020

(c) The Author(s) 2020

\begin{abstract}
We present the case of a 67-year-old man in good health with perirenal hematoma due to a ruptured arterial aneurysm in the kidney. The patient developed weight loss, muscle weakness, multiple mononeuropathy, hypertension, anemia, renal insufficiency, and multiple lacuna infarctions about a month ago. He was admitted to the hospital due to worsening of his symptom. After admission, severe right-flank pain suddenly occurred; he was then transferred to our hospital. Renal angiography revealed bilateral multiple microaneurysms, and the patient was diagnosed with polyarteritis nodosa based on the clinical, radiographic, and histological findings. We performed selective coil embolization to the ruptured aneurysm and administered oral prednisolone along with intravenous methylprednisolone pulse therapy. Cyclophosphamide pulse therapy was also given. The treatment improved clinical and laboratory findings and achieved clinical remission. Selective coil embolization to the bleeding aneurysm of polyarteritis nodosa was minimally invasive and promptly effective. Immunosuppressants proved useful in the regulation of disease activity and the aneurysm.
\end{abstract}

Keywords Polyarteritis nodosa $\cdot$ Microaneurysm $\cdot$ Perirenal hematoma $\cdot$ Selective coil embolization

\section{Introduction}

Polyarteritis nodosa (PAN) is a systemic necrotizing vasculitis of small- or medium-sized arteries [1]. PAN is a rare form of vasculitis with a prevalence of approximately 31

Yasunori Iwata

yiwata7191@gmail.com

1 Department of Nephrology and Laboratory

Medicine, Kanazawa University, 13-1 Takara-machi, Kanazawa 920-8641, Japan

2 Division of Nephrology, Kanazawa University Hospital, 13-1 Takara-machi, Kanazawa 920-8641, Japan

3 Division of Infection Control, Kanazawa University Hospital, 13-1 Takara-machi, Kanazawa 920-8641, Japan

4 Department of Medicine, Hakui General Hospital, 24 Matsusaki, Matoba-machi, Hakui, Ishikawa 925-8502, Japan

5 Division of Blood Purification, Kanazawa University Hospital, 13-1 Takara-machi, Kanazawa 920-8641, Japan

6 Department of Nephrology, Kanazawa Medical University School of Medicine, 1-1 Daigaku, Uchinada, Kahoku, Ishikawa 920-0293, Japan cases per 1 million in Europe [2]. The mean age of onset is approximately 50 years. PAN is more common in men than in women [3]. Whereas most patients are idiopathic and negative for anti-neutrophil cytoplasmic antibodies (ANCA), some are associated with hepatitis B virus (HBV), hepatitis $\mathrm{C}$ virus (HCV), and human immunodeficiency virus (HIV) [4]. The diversity of clinical manifestations ranges from general symptoms, such as fever, weight loss, myalgias, and arthralgia, to organ-specific symptoms. The overall prognosis of PAN can improve with early diagnosis and administration of immunosuppressants, although untreated PAN still exhibits a poor prognosis.

The kidney, peripheral nervous system, and skin are frequently affected by PAN. Kidneys are involved in approximately $50 \%$ of cases. Representative manifestations include hematuria, proteinuria, recent-onset hypertension, and infarction, but PAN is not associated with glomerulonephritis $[3,5]$. Whereas renal artery aneurysms are common, a perirenal hematoma is a rare complication in PAN [6].

In this report, we presented a case of PAN with unilateral perirenal hematoma due to a ruptured renal artery microaneurysm. Selective coil embolization to a unilateral perirenal 
hematoma by the ruptured microaneurysm was successfully conducted without complications. Our patient achieved clinical remission through treatment with oral prednisolone and intravenous methylprednisolone along with cyclophosphamide pulse therapy.

\section{Case report}

A 67-year-old man in good health reported numbness and weakness of his lower legs in June 2010. He presented to the clinic due to the spread of the symptoms to his upper limbs. Magnetic resonance imaging revealed multiple lacuna infarctions. Laboratory analysis revealed anemia (hemoglobin [Hb], $9.8 \mathrm{~g} / \mathrm{dL}$ ) and renal dysfunction (creatine, $2.7 \mathrm{mg} / \mathrm{dL}$ ). He was admitted to a nearby hospital for further examination and was diagnosed with hypertension and multiple mononeuropathy. In addition, laboratory findings revealed increased levels of C-reactive protein (CRP, $16.82 \mathrm{mg} / \mathrm{dL}$ ). After 8 days in the hospital, severe rightflank pain suddenly occurred, and anemia worsened $(\mathrm{Hb}$, $6.8 \mathrm{~g} / \mathrm{dL}$ ). Abdominal computed tomography (CT) without enhancement revealed a right perirenal hematoma. $\mathrm{He}$ was then transferred to our hospital for investigation and treatment.
On admission, his height was $156.0 \mathrm{~cm}$, and his weight was $54.5 \mathrm{~kg}$ (approximately 2-kg loss over months). His blood pressure was 192/114 mm Hg; pulse, $98 \mathrm{bpm}$; and body temperature, $37.1{ }^{\circ} \mathrm{C}$. On physical examination, palpebral conjunctiva was pallid, and he had severe right-flank pain with muscular defense. No skin rush was evident in the extremities, although hypesthesia was detected by neurologic examination. Laboratory findings on admission are presented in Table 1. The results of the urine tests were as follows: protein levels, $2.4 \mathrm{~g} / \mathrm{g} \cdot \mathrm{Cr}$; occult blood $3+$ by dipstick test; red blood cells $\geqq 100 /$ high-power field; and sediment contained granular cast $2+$. The results of serum examinations were as follows: white blood count, $13,610 / \mu \mathrm{L}$ (with $74.0 \%$ neutrophils and $16.0 \%$ eosinophils); hemoglobin, $6.2 \mathrm{~g} / \mathrm{dL}$; platelet count, $32.1 \times 10^{4} / \mu \mathrm{L}$; alkaline phosphatase, $1,867 \mathrm{IU} / \mathrm{L} ; \boldsymbol{\gamma}$-glutamyl transpeptidase $(\gamma$-GTP), $360 \mathrm{IU} / \mathrm{L}$; blood urea nitrogen, $39 \mathrm{mg} / \mathrm{dL} ; \mathrm{Cr}, 1.3 \mathrm{mg} / \mathrm{dL}$; erythrocyte sedimentation rate, $156 \mathrm{~mm}$; C-reactive protein, $11.5 \mathrm{mg} /$ dL; immunoglobulin (Ig) G, $2533 \mathrm{mg} / \mathrm{dL}$; IgA, $306 \mathrm{mg} / \mathrm{dL}$; IgM, $106 \mathrm{mg} / \mathrm{dL}$; C3, $83 \mathrm{mg} / \mathrm{dL} ; \mathrm{C} 4,15 \mathrm{mg} / \mathrm{dL}$; and CH50, $48 \mathrm{U} / \mathrm{mL}$. ANA, PR3-ANCA, MPO-ANCA, anti-GBM antibody, and HBs-antigenemia were not detected. Contrast-enhanced CT revealed bilateral pleural effusion, right small renal infarction, and right perirenal hematoma. CT angiography revealed multiple small aneurysmal dilatations

Table 1 Laboratory data on admission

\begin{tabular}{|c|c|c|c|c|c|}
\hline Urinalysis & & Blood chemistry & & Serology & \\
\hline $\mathrm{pH}$ & 5.5 & $\mathrm{TP}$ & $6.9(\mathrm{~g} / \mathrm{dL})$ & $\operatorname{ESR}(1 \mathrm{~h})$ & $156(\mathrm{~mm})$ \\
\hline \multirow[t]{2}{*}{ Protein } & $2+$ & Alb & $2.6(\mathrm{~g} / \mathrm{dL})$ & CRP & $11.5(\mathrm{mg} / \mathrm{dL})$ \\
\hline & $2.4(\mathrm{~g} / \mathrm{g} \cdot \mathrm{Cr})$ & AST & 32 (IU/L) & $\operatorname{IgG}$ & $2533(\mathrm{mg} / \mathrm{dL})$ \\
\hline Glucose & $2+$ & ALT & 14 (IU/L) & $\operatorname{Ig} \mathrm{A}$ & $306(\mathrm{mg} / \mathrm{dL})$ \\
\hline Occult blood & $3+$ & ALP & 1867 (IU/L) & $\operatorname{IgM}$ & $106(\mathrm{mg} / \mathrm{dL})$ \\
\hline $\mathrm{RBC}$ & $\geqq 100$ (/HPF) & $\gamma$-GTP & 360 (IU/L) & $\mathrm{C} 3$ & $83(\mathrm{mg} / \mathrm{dL})$ \\
\hline WBC & 10-19 (/HPF) & T-bil & $0.6(\mathrm{mg} / \mathrm{dL})$ & $\mathrm{C} 4$ & $15(\mathrm{mg} / \mathrm{dL})$ \\
\hline Hyaline cast & $2+$ & $\mathrm{UN}$ & $39(\mathrm{mg} / \mathrm{dL})$ & $\mathrm{CH} 50$ & $48(\mathrm{U} / \mathrm{mL})$ \\
\hline Granular cast & $2+$ & $\mathrm{Cr}$ & $1.3(\mathrm{mg} / \mathrm{dL})$ & ANA & $<20$ \\
\hline $\mathrm{RBC}$ cast & - & UA & $7.9(\mathrm{mg} / \mathrm{dL})$ & PR3-ANCA & $<10(\mathrm{EU})$ \\
\hline Complete blood cell count & & $\mathrm{Na}$ & $133(\mathrm{mEq} / \mathrm{L})$ & MPO-ANCA & $<10(\mathrm{EU})$ \\
\hline WBC & $13600(/ \mu \mathrm{L})$ & $\mathrm{K}$ & $4.6(\mathrm{mEq} / \mathrm{L})$ & Anti-GBM antibody & $<10(\mathrm{IU} / \mathrm{mL})$ \\
\hline $\mathrm{Neu}$ & $74(\%)$ & $\mathrm{Cl}$ & $103(\mathrm{mEq} / \mathrm{L})$ & $\mathrm{RF}$ & $<10(\mathrm{IU} / \mathrm{mL})$ \\
\hline Lymph & $7(\%)$ & $\mathrm{Ca}$ & $7.8(\mathrm{mg} / \mathrm{dL})$ & Ferritin & $680(\mathrm{ng} / \mathrm{mL})$ \\
\hline Eos & $16(\%)$ & IP & $3.3(\mathrm{mg} / \mathrm{dL})$ & Cryoglobulin & - \\
\hline Baso & $0(\%)$ & T-Cho & 123 (mg/dL) & HBs-Ag & - \\
\hline Mono & $3(\%)$ & TG & 115 (mg/dL) & HBV-DNA & - \\
\hline $\mathrm{RBC}$ & $\left.210 \times 10^{4}(/ \mu \mathrm{L})\right)$ & HDL-Cho & $23(\mathrm{mg} / \mathrm{dL})$ & & \\
\hline $\mathrm{Hb}$ & $6.2(\mathrm{~g} / \mathrm{dL})$ & BS & $151(\mathrm{mg} / \mathrm{dL})$ & & \\
\hline $\mathrm{Ht}$ & $18.6(\%)$ & LDH & 209 (IU/L) & & \\
\hline Ret & $9.2(/ \mu \mathrm{L})$ & Amy & 43 (IU/L) & & \\
\hline Plt & $32.1 \times 10^{4}(/ \mu \mathrm{L})$ & $\mathrm{CK}$ & 25 (IU/L) & & \\
\hline
\end{tabular}

ESR erythrocyte sedimentation rate, ANA anti-nuclear antibody, $P R 3-A N C A$ serine proteinase 3 anti-neutrophil cytoplasmic antibody, $M P O$ $A N C A$ myeloperoxidase anti-neutrophil cytoplasmic antibody, $R F$ rheumatoid factor, $G B M$ glomerular basement membrane 
in the intrarenal branches of the bilateral renal arteries and the intrasplenic branches of the splenic artery (Fig. 1a-c). Emergency selective coil embolization was conducted to the right renal artery aneurysm, which was responsible for the bleeding (Fig. 2). To obtain a definitive diagnosis, we performed a left sural nerve biopsy (Fig. 3). We confirmed a small arterial occlusion with inflammatory cell infiltration in the sural nerve tissue, although a histological examination did not reveal fibrinoid necrosis or granuloma. Collectively, and based on his clinical and radiographic findings, we diagnosed polyarteritis nodosa.

On the fifth hospital day, we started oral prednisolone therapy at $40 \mathrm{mg} /$ day. On the 8 th and 15 th hospital days, intravenous methylprednisolone pulse $(500 \mathrm{mg} /$ day $)$ therapy was started for 3 consecutive days. Although these therapies suppressed the disease activity, including inflammatory response, urine protein, and pleural effusion, the patient failed to achieve remission. Intravenous pulse cyclophosphamide therapy was, therefore, given on the 30th day. Clinical symptoms such as numbness and weakness of limbs
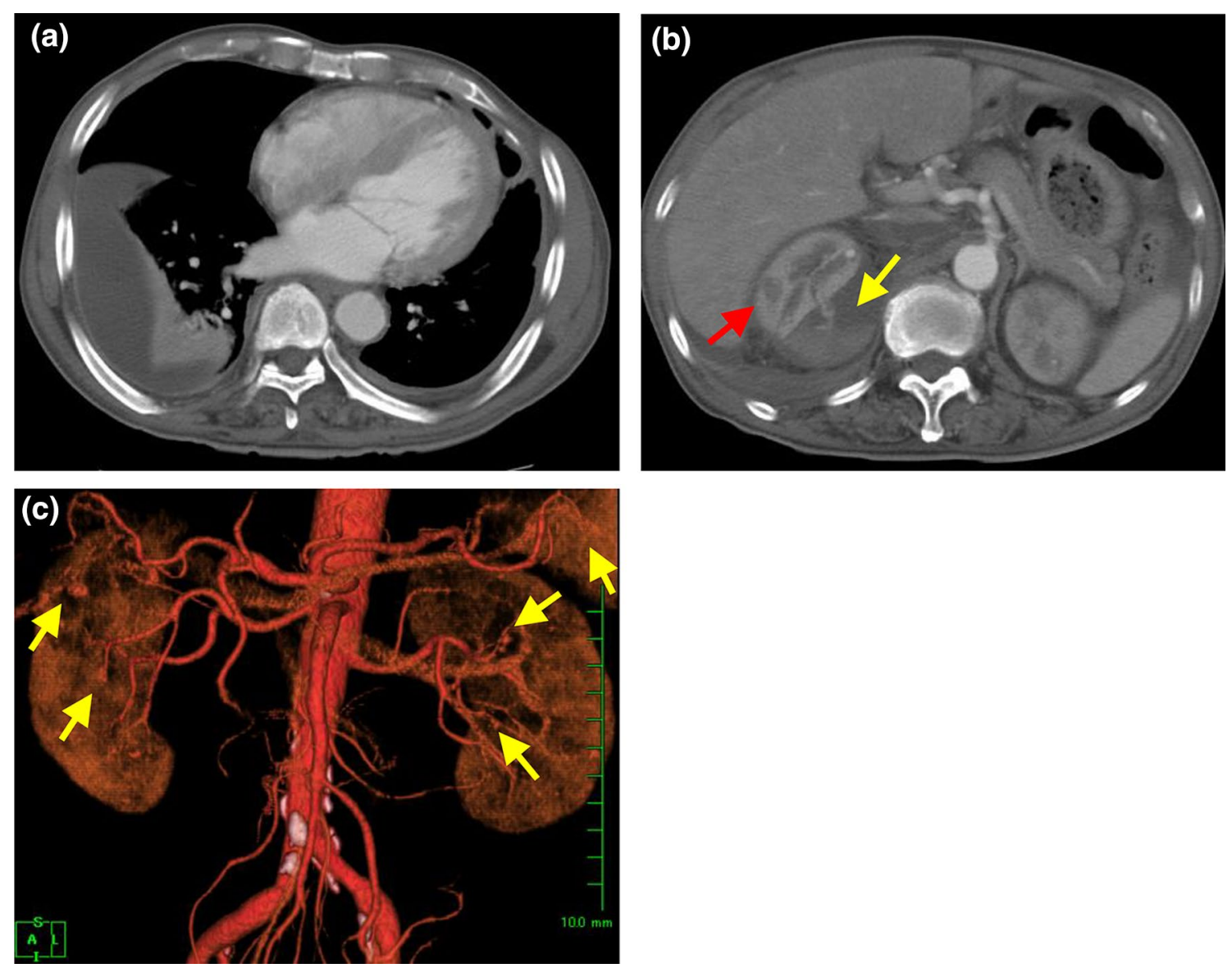

Fig. 1 Contrast-enhanced computed tomography. a Bilateral pleural effusion was apparent. b CT scan image showing a right perirenal hematoma with extravasation of contrast media (yellow arrow) and a small renal infarction (red arrow). c CT angiography showing mul- gradually diminished, and laboratory findings dramatically improved. Moreover, contrast-enhanced CT revealed the disappearance of pleural effusion and the decreased size of perirenal hematoma concomitant with aneurysms. The patient was then transferred to another hospital for rehabilitation training (Fig. 4).

\section{Discussion}

Here, we presented a case of PAN with a unilateral perirenal hematoma due to a ruptured arterial aneurysm.

PAN is diagnosed based on clinical manifestations, angiography, and histopathology. Our patient was healthy but had developed weight loss, muscle weakness, multiple mononeuropathies, hypertension, anemia, renal insufficiency, and multiple lacuna infarctions for about a month. He suffered from a sudden onset of right-flank pain with a perirenal hematoma due to a ruptured renal aneurysm. He also exhibited bilateral pleural effusion without an elevated ANCA tiple small aneurysmal dilatations in the intrarenal branches of the bilateral renal arteries and in the intrasplenic branches of the splenic artery (yellow arrow) 

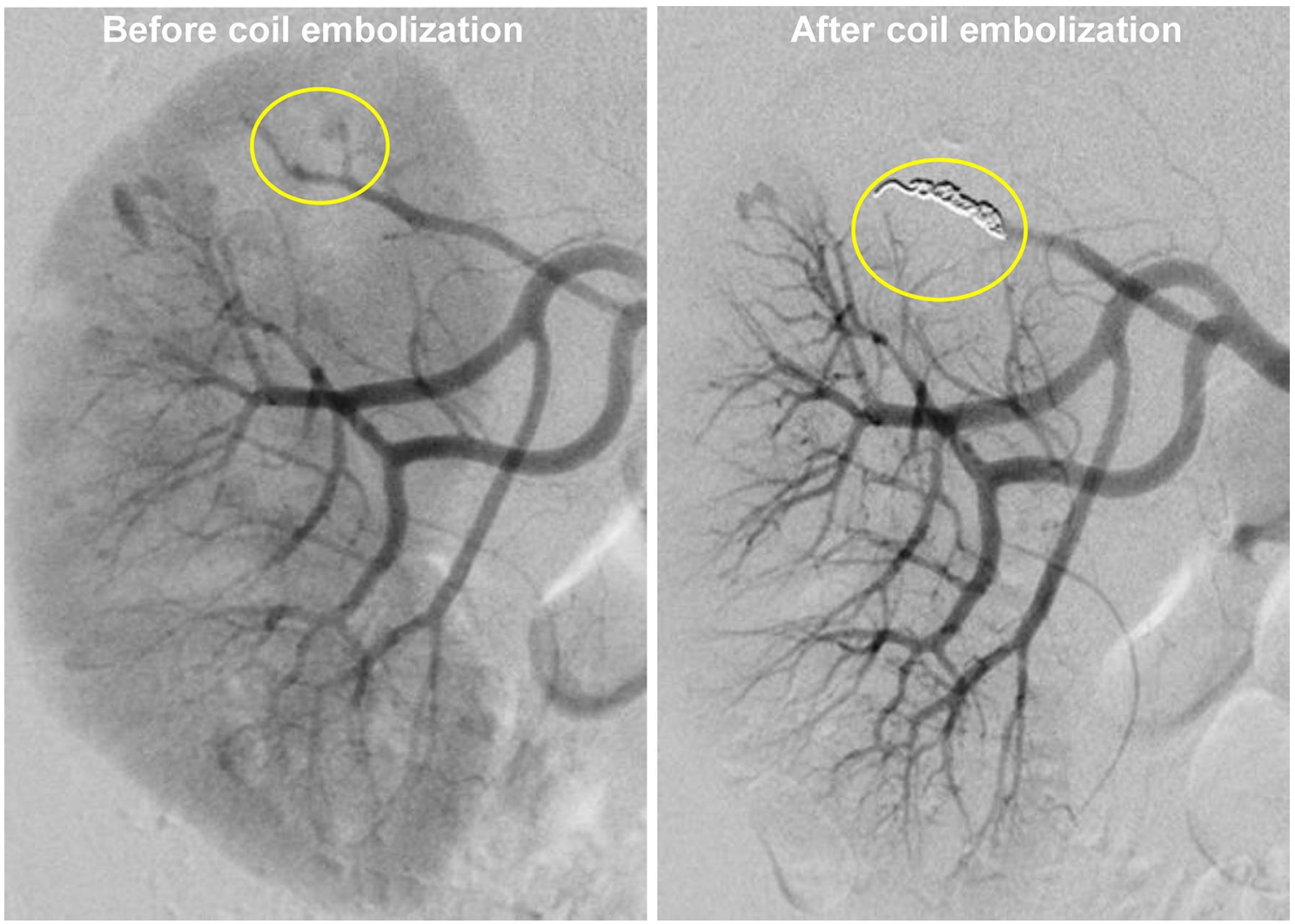

Fig. 2 Selective coil embolization to the right renal artery aneurysm. Catheter angiography showing selective coil embolization to the bleeding renal artery aneurysm (yellow circle)

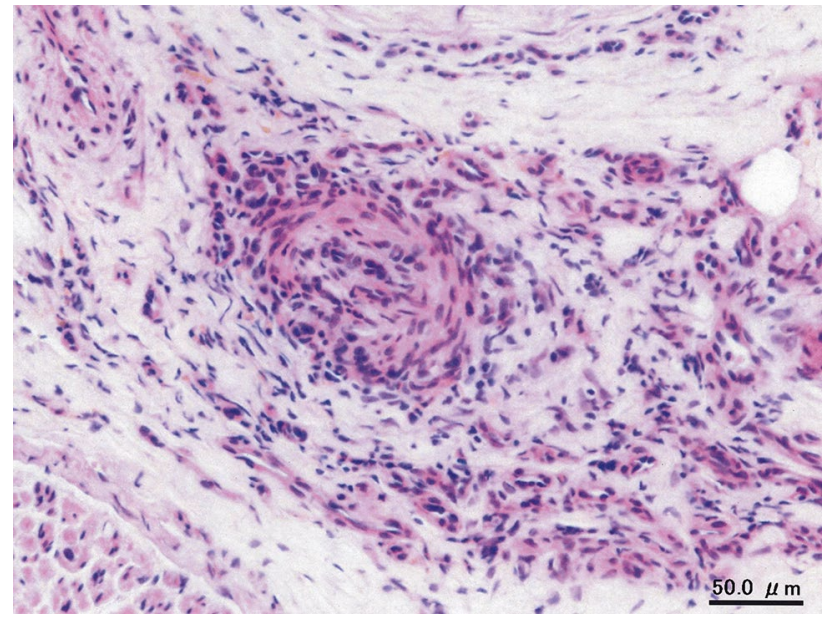

Fig. 3 Left sural nerve biopsy. Mononuclear cell infiltration in small arteries with occlusion and recanalization of the vascular lumen (hematoxylin and eosin staining; original magnification $\times 400$ )

titer. The presence of three or more American College of Rheumatology (ACR) criteria revealed a sensitivity of $82 \%$ and specificity of $86 \%$ in the cases with PAN [7]. Our patient fulfilled 5 of the 10 ACR criteria and could have also been diagnosed with PAN based on the Chapel Hill criteria [1]. Consistent with this case, $93 \%$ of ANCA-negative patients with arteriographic anomalies were diagnosed as PAN rather than microscopic polyangiitis in a review of 949 patients with systemic vasculitis [8].

Our patient presented with a unilateral perirenal hematoma due to a ruptured renal artery aneurysm. In a survey of 348 patients with PAN, 104 (66.4\%) had kidney microaneurysms [5]. In addition, the frequency of aneurysms in PAN increased with clinical severity [9]. Hypertension has been reported as a risk of aneurysm rupture [10]. In this case, hypertension had not been revealed in an annual medical checkup, indicating that it occurred in a short period. Renal hemorrhages are typically caused by an arterial aneurysmal rupture and rarely by renal artery dissection or rupture [6]. Spontaneous perirenal hematoma was first reported as a complication of PAN by Schmidt in 1908 [11]. Although a perirenal hematoma caused by an aneurysmal rupture is a common complication, the frequency of renal artery dissection or rupture-induced perirenal hematoma is relatively low [6]. Mortality is reportedly $50 \%$, and the recurrent bleeding rate is $18 \%$ with nephrectomy therapy [6]. Currently, transcatheter selective renal artery embolization is typically performed instead of nephrectomy. With this therapy, favorable 


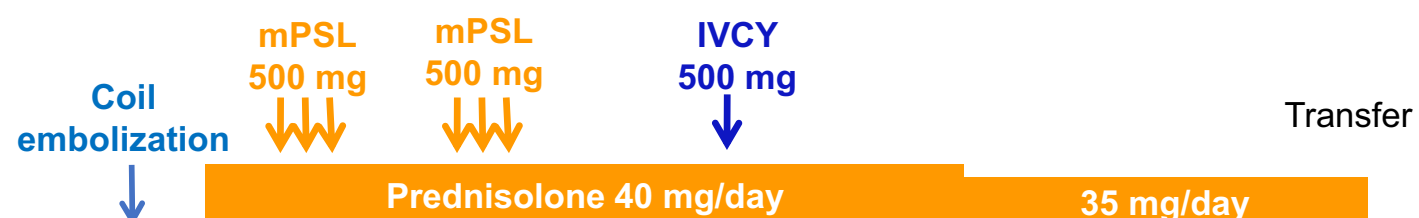

\section{Right flank pain}

\section{Numbness and weakness of limb}
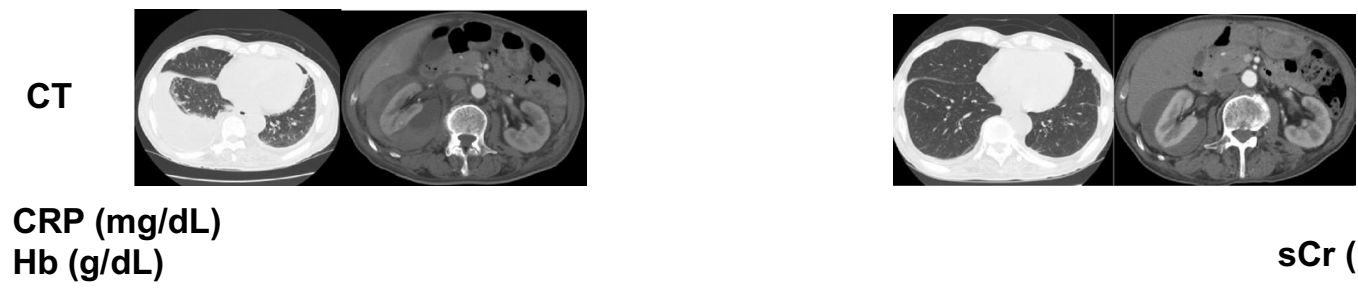

$\mathrm{Hb}(\mathrm{g} / \mathrm{dL})$

$\mathrm{sCr}(\mathrm{mg} / \mathrm{dL})$

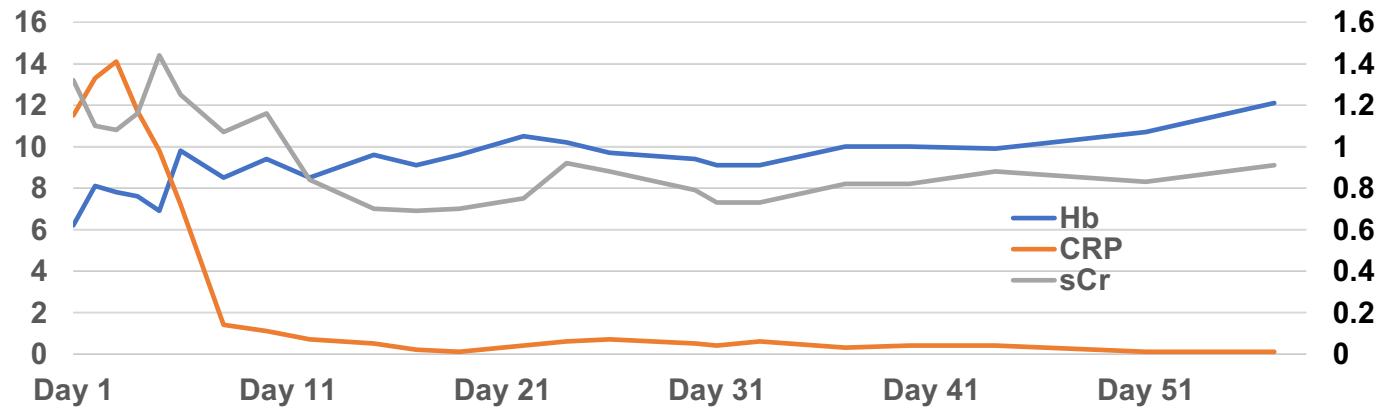

Fig. 4 Clinical course of the case. $m P S L$ methylprednisolone, IVCY intravenous cyclophosphamide

outcomes have been reported, regardless of embolic material, unilateral, or bilateral hematoma [6,12-15]. The procedure-related mortality of selective embolization is 3.6\% [16]. The frequencies of micro-renal infarction, lateral abdominal pain, and fever are $17.6 \%, 11.8 \%$, and $5.9 \%$, respectively [17]. Fortunately, in our patient, selective coil embolization to the ruptured aneurysm was conducted successfully with no complications.

In 1996, the prognostic Five-Factor Score (FFS) was established to evaluate the outcomes and mortality of PAN, Churg-Strauss syndrome [18]. The revised FFS (2011) indicates the prognosis of PAN by four factors: age (older than 65 years), renal insufficiency (serum creatinine $>1.7 \mathrm{mg} / \mathrm{dL}$ ), cardiac insufficiency, and severe gastrointestinal involvement [19]. The FFS of the case was 2 , based on multiple bilateral renal aneurysms and failure to achieve remission by glucocorticoid monotherapy. A previous report indicated that cyclophosphamide therapy may improve microaneurysms of PAN [20] and is recommended for cases of PAN with an FFS $\geqq 1$ as induction therapy [3]. We, therefore, administered cyclophosphamide, resulting in remission. The 5-year survival of PAN has improved from $13 \%$ in untreated patients to approximately $80 \%$ in patients treated with glucocorticoid and cyclophosphamide [5, 21, 22]. However, as the 5-year survival rate in PAN with an FFS $\geqq 2$ is $65.0 \%$ [5], careful follow-up is necessary.

In summary, a case of PAN with unilateral perirenal hematoma due to a ruptured renal artery microaneurysm was described. Selective coil embolization to the ruptured renal microaneurysm was minimally invasive and promptly effective. In addition, therapy with immunosuppressants resulted in clinical remission.

Acknowledgements The authors would like to thank K. Sakai and M. Yamada for the histological assessment of the sural nerve biopsy.

\section{Compliance with ethical standards}

Conflict of interest The authors have declared that no Conflict of interest exists.

Research involving human participants All procedures performed in studies involving human participants were in accordance with the ethical standards of the institutional and/or national research committee and with the 1964 Helsinki declaration and its later amendments or comparable ethical standards.

Informed consent Informed consent was obtained from all individual participants included in the study. 
Open Access This article is licensed under a Creative Commons Attribution 4.0 International License, which permits use, sharing, adaptation, distribution and reproduction in any medium or format, as long as you give appropriate credit to the original author(s) and the source, provide a link to the Creative Commons licence, and indicate if changes were made. The images or other third party material in this article are included in the article's Creative Commons licence, unless indicated otherwise in a credit line to the material. If material is not included in the article's Creative Commons licence and your intended use is not permitted by statutory regulation or exceeds the permitted use, you will need to obtain permission directly from the copyright holder. To view a copy of this licence, visit http://creativecommons.org/licenses/by/4.0/.

\section{References}

1. Jennette JC, Falk RJ, Bacon PA, Basu N, Cid MC, Ferrario F, et al. 2012 revised international Chapel Hill consensus conference nomenclature of vasculitides. Arthritis Rheum. 2013;65:1-11.

2. Hernandez-Rodriguez J, Alba MA, Prieto-Gonzalez S, Cid MC. Diagnosis and classification of polyarteritis nodosa. J Autoimmun. 2014;48-49:84-9.

3. De Virgilio A, Greco A, Magliulo G, Gallo A, Ruoppolo G, Conte M, et al. Polyarteritis nodosa: a contemporary overview. Autoimmun Rev. 2016;15:564-70.

4. Karadag O, Jayne DJ. Polyarteritis nodosa revisited: a review of historical approaches, subphenotypes and a research agenda. Clin Exp Rheumatol. 2018;36(Suppl 111):135-42.

5. Pagnoux C, Seror R, Henegar C, Mahr A, Cohen P, Le Guern V, et al. Clinical features and outcomes in 348 patients with polyarteritis nodosa: a systematic retrospective study of patients diagnosed between 1963 and 2005 and entered into the French Vasculitis Study Group Database. Arthritis Rheum. 2010;62:616-26.

6. Smith DL, Wernick R. Spontaneous rupture of a renal artery aneurysm in polyarteritis nodosa: critical review of the literature and report of a case. Am J Med. 1989;87:464-7.

7. Lightfoot RW Jr, Michel BA, Bloch DA, Hunder GG, Zvaifler NJ, McShane DJ, et al. The American College of Rheumatology 1990 criteria for the classification of polyarteritis nodosa. Arthritis Rheum. 1990;33:1088-93.

8. Henegar C, Pagnoux C, Puechal X, Zucker JD, Bar-Hen A, Le Guern $\mathrm{V}$, et al. A paradigm of diagnostic criteria for polyarteritis nodosa: analysis of a series of 949 patients with vasculitides. Arthritis Rheum. 2008;58:1528-38.

9. Ewald EA, Griffin D, McCune WJ. Correlation of angiographic abnormalities with disease manifestations and disease severity in polyarteritis nodosa. J Rheumatol. 1987;14:952-6.

10. Choy CW, Smith PA, Frazer C, Jeffrey GP. Ruptured hepatic artery aneurysm in polyarteritis nodosa: a case report and literature review. Aust NZ J Surg. 1997;67:904-6.
11. Schmidt JE. Ueber Periarteriitis nodosa. Beitr Path Anat. 1908:43:455-69.

12. Ullah A, Marwat A, Suresh K, Khalil A, Waseem S. Spontaneous retroperitoneal hematoma: a rare presentation of polyarteritis nodosa. J Investig Med High Impact Case Rep. 2019;7:2324709619858120.

13. Hidalgo J, Crego M, Montlleo M, de la Torre P, Bover J, Caparros $\mathrm{J}$, et al. Embolization of a bleeding aneurysm in a patient with spontaneous perirenal haematoma due to Polyarteritis nodosa. Arch Esp Urol. 2005;58:694-7.

14. Zapzalka DM, Thompson HA, Borowsky SS, Coleman-Steenson CC, Mahowald ML, O'Connell KJ. Polyarteritis nodosa presenting as spontaneous bilateral perinephric hemorrhage: management with selective arterial embolization. J Urol. 2000;164:1294-5.

15. Allen AW, Waybill PN, Singh H, Brown DB. Polyarteritis nodosa presenting as spontaneous perirenal hemorrhage: angiographic diagnosis and treatment with microcoil embolization. J Vasc Interv Radiol. 1999;10:1361-3.

16. Jander HP, Russinovich NA. Transcatheter gelfoam embolization in abdominal, retroperitoneal, and pelvic hemorrhage. Radiology. 1980;136:337-44.

17. Soga Y, Sakai K, Nobuyoshi M. Renal artery aneurysm treatment with coil embolization. Catheter Cardiovasc Interv. 2007;69:697-700.

18. Guillevin L, Lhote F, Gayraud M, Cohen P, Jarrousse B, Lortholary $\mathrm{O}$, et al. Prognostic factors in polyarteritis nodosa and ChurgStrauss syndrome. A prospective study in 342 patients. Medicine (Baltimore). 1996;75:17-28.

19. Guillevin L, Pagnoux C, Seror R, Mahr A, Mouthon L, Le Toumelin $\mathrm{P}$, et al. The Five-Factor Score revisited: assessment of prognoses of systemic necrotizing vasculitides based on the French Vasculitis Study Group (FVSG) cohort. Medicine (Baltimore). 2011;90:19-27.

20. Harada M, Yoshida H, Ikeda H, Yoshida T, Takedatsu H, Nagamatsu $\mathrm{H}$, et al. Polyarthritis nodosa with mesenteric aneurysms demonstrated by angiography: report of a case and successful treatment of the patient with prednisolone and cyclophosphamide. J Gastroenterol. 1999;34:702-5.

21. Balow JE. Renal vasculitis. Kidney Int. 1985;27:954-64.

22. Frohnert PP, Sheps SG. Long-term follow-up study of periarteritis nodosa. Am J Med. 1967;43:8-14.

Publisher's Note Springer Nature remains neutral with regard to jurisdictional claims in published maps and institutional affiliations. 